\title{
Food Security and Coping Strategies amongst Medium Income Earners in Maiduguri Metropolis of Borno State, Nigeria.
}

\author{
Ahmed, Funmilola Fausat \& Dotti, Rakiya Yelwa \\ Department of Economics, University of Maiduguri, Nigeria.
}

\begin{abstract}
This paper examined the determinants of food security among medium income households in Maiduguri Metropolis of Borno State Nigeria. Data for the study were selected from 120 medium income households using purposive and multi-stage random sampling techniques. Descriptive statistics, Cost-ofcalories method, Logit model and household dietary diversity scores were used as analytical techniques for the study. Based on the recommended daily energy levels of $2260 \mathrm{kcal}$, a food security line of N26,956.00 per adult equivalent per year was obtained for the households and about 67\% of the sample households are therefore food secure. The Logit analysis revealed that the major determinants that positively influence food security in the study area among others are income, level of education, assets, farm enterprise, extension agent's contact and diet diversity while household size negatively influence food security. Therefore, it is imperative that government should give adequate priority and attention to policy measures directed towards educating and provision of better family planning. Also, improving wage earning capacity and exploring income diversification opportunities are crucial in enhancing food security status and general welfare of households in the study area.
\end{abstract}

\section{Introduction}

Agricultural production till date remains the mainstay of the Nigerian economy. It is the main source of food for most of the population. Agriculture provides the means of livelihood for over $70 \%$ of the population. It is a major source of food for the populace, raw materials for the agro-allied industries and a potent source of the much needed foreign exchange (Kwaghe, 2006). One of the key objectives of the agricultural sector in Nigeria is the provision of sufficient food at all times for the ever-growing population. Food is any substance consumed to provide nutritional support for the body. In order to maintain good health and optimal performance, food has to be provided in adequate quality and quantity, hence, the need for food security. According to The World Food Summit 1996 "Food security exists when all people, at all times have physical and economic access to enough safe and nutritious food to meet their dietary needs and food preferences for an active and healthy lifestyle". The Food and Agricultural Organization (1998) defined food security as a condition in which all people at all times have access to sufficient and safe diet. Food security is not only the availability but also the accessibility, procurement and intake of adequate food in both quality and quantity by in individuals, households, communities or regions (Nyangwesoi et al., 2007).

Given the role of agriculture in Nigerian economy, the poor performance of the sector directly creates supply shortages and indirectly creates demand shortages thereby denying the households access to sufficient income. Among the development problems facing Nigeria as observed by Hall (2002) and Sanusi et al. (2006), food insecurity ranks topmost. The level of food insecurity has continued to rise steadily since the 1980 s. It rose from about $18 \%$ in 1986 to about $41 \%$ in 2004. Maziya-Dixton et al. (2004) also reported that over $40 \%$ of households across all agro-ecological zones in Nigeria face the problem of severe food insecurity. Food insecurity therefore remains a fundamental challenge in Nigeria. The concept of the food problem is complex and goes beyond the simplistic idea of a country's inability to feed its population. Furthermore, despite Nigeria's endowment in food supply, it has remained one of the poorest economies of the world with about $70 \%$ of the population living on less than $\mathrm{N} 100$ (0.7 US Dollars) per day (FOS, 2004). In recent times, there have been threats of hunger and poverty. Of the entire population of farmers in Nigeria, small holder farmers constitute $80 \%$ with inefficient production systems which has resulted in a sustained fall in the Net Domestic Product (NDP) of the economy.

In the history of man, there has never been enough food available to properly feed the whole human family. In Nigeria, food import has also become a feature to rely upon and this is no other name than food insecurity. Attempts by governments (particularly at the Federal Level) to import food massively to solve the food supply deficits in Nigeria presents a situation at the national level which does not guarantee food security among various households in the country. Thus, adequate food supply at the national level does not automatically lead to food security for many households the bulk of which is poor and does not have sufficient purchasing power to procure the food it needs in adequate quantity and quality. It is therefore noteworthy that 
achieving food security requires that the aggregate availability of physical supplies of food is sufficient, accessible and that utilization of those food supplies is appropriate to meet the specific dietary needs of households in Maiduguri Metropolis of Borno State, Nigeria.

Also, despite the growing concern of improving food security, the measurement and determinants of food security among income groups in Maiduguri Metropolis of Borno State, Nigeria is not well-documented. As a result, there is a need to empirically measure, examine the determinants of food security and outline the coping strategies adopted by middle income households in the study area. The extent that the study will identify the determinants of household food security will help in providing information for the formulation of appropriate policies that can mitigate food insecurity, especially amongst these households in the urban area in Nigeria. This is the whole essence of the study.

\section{Methodology}

The Study Area: The study was carried out in Maiduguri Metropolis, the capital city of Borno State. It is located on latitude $115^{\circ} \mathrm{N}$ and latitude $135^{\circ} \mathrm{E}$. Maiduguri is the largest and main commercial city in the North Eastern Nigeria. It occupies an area of 69,436 square kilometers $\left(\mathrm{km}^{2}\right)$. According to the 2006 population census, Maiduguri has a population of 521,492 people with an annual growth rate of $2.8 \%$. Maiduguri Metropolis is ecologically characterized as a sahelian savannah with mainly grasses, shrubs, and few trees. The climate condition of the State is hot and dry for most part of the year. It has low rainfall which ranges from 500 $\mathrm{mm}$ to $1000 \mathrm{~mm}$ annually and a low relative humidity ranging from $42 \%$ to $49 \%$. The average temperature is about $20^{\circ} \mathrm{C}$ (Maryah, 2005). The majority of the populace of the Maiduguri Metropolis is civil servants, traders, military and paramilitary and artisans. Major crops cultivated in the study area are millet, sorghum, maize, groundnut, wheat, cowpea and the major livestock reared are cattle, sheep, goats and poultry production hence the determinants of food security and food security status of the medium-income households (MIH) could reflect to some extent the food security situation in the State.

\section{Data collection}

Both purposive and multi-stage random sampling techniques were employed for this study. The purposive sampling was used to select four ministries at the Federal Secretariat Maiduguri namely ministry of health, education, agriculture and works and housing. The multi-stage sampling technique was used in selecting middle income earners from the earlier (purposively) chosen ministries. In the first stage, three departments/units were chosen from each of the four ministries giving a total of 12 departments/units. The second stage involved selection of workers based on their income levels (7-10 grade levels). Thirteen (13) respondents were randomly selected from each of these departments making a total of 156 middle class salary earners in the civil service. However, data from only 120 respondents were analyzed due to inconsistency and/or incompleteness.

Data measurement and analytical technique: Descriptive statistics and inferential statistics (the cost-of-calories [COC], Logit models and Household Dietary Diversity Score [HDDS]) were the analytical techniques used for the study.

Descriptive statistics: Descriptive statistics was used to examine the socio-economic characteristics of respondents. These techniques include means, frequencies and percentages which were used to catalogue and categorize households by socio-economic characteristics.

Cost-of-Calories [COC]: The COC method proposed by Greer and Thorbecke (1986) was used to estimate the food security line. The method yields a value that is usually close to the minimum calorie requirements for human survival. A minimum level of nutrition necessary to maintain healthy living was identified. This minimum level is referred to as the 'food security line' for the area under study, below which people are classified as food insecure, subsisting on inadequate nutrition. Calorie adequacy was estimated by dividing the estimated calorie supply for the households by the household size adjusted for adult equivalence using the consumption factor for age-sex categories. The food security line is given as:

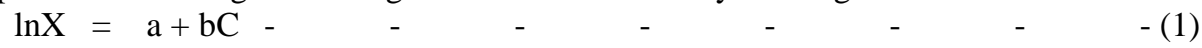

Where:

$\mathrm{X}=$ adult equivalent food expenditure (in Naira) and

$\mathrm{C}=$ actual calorie consumption per adult equivalent of a household (in kilo cal).

The calorie content of the recommended minimum daily nutrients level (L) 2260 Kilocalories employed by (Babatunde et al., (2007): FAO, 2009; Oluyole 2009) was used to determine the food security line S using the equation:

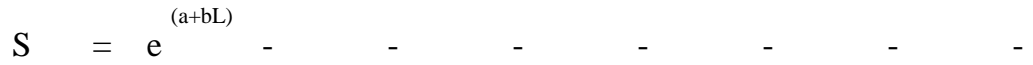

Where:

$\mathrm{S}=$ cost of buying the minimum calorie intake (food security line); 
$\mathrm{a}=$ Intercept;

$\mathrm{b}=$ Coefficient of the calorie consumption;

$\mathrm{L}=\mathrm{FAO}$ recommended minimum daily energy (calorie) level.

Table 1: Conversion Factors for Calorie Requirement for different Age Groups.

\begin{tabular}{lll}
\hline Years of age & Male & Female \\
\hline $0-1$ & 0.27 & 0.27 \\
$2-3$ & 0.45 & 0.45 \\
$4-6$ & 0.61 & 0.61 \\
$7-9$ & 0.73 & 0.73 \\
$10-12$ & 0.86 & 0.78 \\
$13-15$ & 0.96 & 0.83 \\
$16-19$ & 1.02 & 0.77 \\
20 and above & 1.00 & 0.73 \\
\hline
\end{tabular}

Source: FOS, (2004)

Logit Model: In the Logit model, the data on the dependent variable (food security status) is bivariate, that is, food secure and food insecure households. The model assumes that being food secure is a continuous status. The model expresses households' food security status as a function of linear combination of observable explanatory variables, some unknown parameters and an error term $(e)$. The implicit form of the model is expressed as:

$\mathrm{m}$

$$
\mathrm{Y}_{\mathrm{i}}=\mathrm{g}\left(I_{i}\right)
$$

$$
I_{i}=\mathrm{b}_{\mathrm{o}} \sum_{\mathrm{j}=1} \mathrm{bjXji}
$$

Where:

$Y_{i}$ is the observed response for the ith observation (i.e., the binary variable, $Y_{i}=1$ for a food secure household and $Y_{\mathrm{i}}=0$ for a food insecure household); $I_{i}$ is an underlying and unobserved stimulus index for the $\mathrm{i}^{\text {th }}$ observation for each household; if $I_{i}{ }^{*} \geq I_{i}$ the household is observed to be food secure, if $I_{i}{ }^{*} \leq I_{i}$ the household is observed to be food insecure; $\mathrm{g}$ is the functional relationship between the field observations $\left(\mathrm{Y}_{\mathrm{i}}\right) ;\left(I_{i}^{*}\right)$ the stimulus index determines the probability of being food secure; and $\left(I_{i}\right)$ the stimulus index determines the probability of being food insecure. The empirical model used for determining factors that influenced food security status among low-income households in Maiduguri was specified as:

Therefore, for the ith observation (a household)

$$
I_{i}=\text { bo }+b_{1} X_{1}+b_{2} X_{2}+b_{3} X_{3}+b_{4} X_{4}+b_{5} X_{5}+b_{6} X_{6}+b_{7} X_{7}+b_{8} X_{8}+b_{9} X_{9} \quad b_{10} X_{10}+b_{11} X_{11}+b_{12} X_{12}
$$

$+b_{13} X_{13}+b_{14} X_{14}+b_{15} X_{15}+b_{16} X_{16}+e-$

where:

$\mathrm{P}_{\mathrm{i}}=$ the probability of an $\mathrm{i}^{\text {th }}$ household being food secure stands for dummy, $\mathrm{X}_{\mathrm{i}}=$ vector of explanatory variables which are defined as: $X_{1}=$ Age of household head (AGE) in years; $X_{2}=$ Income of household (HHINC) in Naira; $X_{3}=$ Farm size of a household (FARMSZ) in hectares; $X_{4}=$ Household size $\left(\right.$ HHSZ); $X_{5}=$ Farming experience $(\mathrm{FARMEXP})$ in years; $\mathrm{X}_{6}=\mathrm{Co}$-operative membership; $(\mathrm{COOP}) \mathrm{D}=1$, if yes; $\mathrm{D}=0$, otherwise; $\mathrm{X}_{7}=$ Level of education (EDUC) in years; $\mathrm{X}_{8}=$ Sex of household head (SEX) D = 1 for male, $\mathrm{D}=0$ for female; $\mathrm{X}_{9}=$ Household assets (HHAST) in Naira; $\mathrm{X}_{10}=$ Household production enterprise (FARMENT); D = 1, if yes; $\mathrm{D}=$ 0 , otherwise; $X_{11}=$ Household head's access to credit facilities (CREDIT) $D=1$ if yes, otherwise $D=0 ; X_{12}=$ Child dependency ratio $(\mathrm{CDR}) ; \mathrm{X}_{13}=$ Household head's access to extension agents (EXTAG) $\mathrm{D}=1$ if yes, otherwise $\mathrm{D}=0 ; \mathrm{X}_{14}=$ Hired Labour $(\mathrm{HLAB})$ in man/day and $\mathrm{X}_{15}=$ Family Labour (FLAB) in Naira; bo = constant; and e = error term.

A priori Expectations: It was expected that the independent variables such as household income, membership of cooperative, educational level of household head, ownership of assets, household enterprise, nutrition education of household head, farm size, farming experience, family labour and access to extension agents would have positive influence on the level of food security in semi-urban and urban settlements. Age of the household head, gender, hired labour, and family size would have negative influence on the level of food security in the study area.

\section{Socioeconomic Characteristics of Households}

\section{Results And Discussion}

The socioeconomic characteristics of respondents examined are discussed in Table 2. The sex distribution of the household heads in Table 2 shows that majority (92\%) were males. Majority of the household heads, approximately, $71.6 \%$ in the MIH were in their active and productive age range of less than 50 years and 
about 53\% had household size of between 5-9 persons. The pattern of distribution of educational qualification revealed that about $81 \%$ among the MIH had formal education. Educational levels of these respondents were also reflections of their social status and income levels hence low level of illiteracy among the MIH. Majority of these households engage in farming, however, about $62 \%$ of the MIH had less than two hectares in agricultural production, $49.2 \%$ had no farming experience and majority $(98 \%)$ had no extension contact.

Table 2: Distribution of Households by Social Factors

\begin{tabular}{|c|c|c|}
\hline Social Factors & \multicolumn{2}{|c|}{ Medium- income Households } \\
\hline \multicolumn{3}{|l|}{ Sex } \\
\hline Male & 110 & 91.7 \\
\hline Female & 10 & 8.3 \\
\hline \multicolumn{3}{|l|}{ Age (years) } \\
\hline $20-29$ & 10 & 8.3 \\
\hline $30-39$ & 31 & 25.8 \\
\hline $40-49$ & 45 & 37.5 \\
\hline $50-59$ & 34 & 28.3 \\
\hline \multicolumn{3}{|l|}{ Household size } \\
\hline Less than 5 & 35 & 29.2 \\
\hline $5-9$ & 64 & 53.3 \\
\hline $10-14$ & 7 & 5.8 \\
\hline Above 15 & 14 & 11.7 \\
\hline \multicolumn{3}{|l|}{ Farm size (hectares) } \\
\hline Less than 2 & 74 & 61.6 \\
\hline $2-3.99$ & 35 & 29.2 \\
\hline $4-5.99$ & 11 & 9.2 \\
\hline \multicolumn{3}{|l|}{ Level of formal education (years) } \\
\hline No education & - & - \\
\hline Quranic & 3 & 2.5 \\
\hline Primary sch. (not completed) & 6 & 5 \\
\hline Primary sch. (completed) & 10 & 8.3 \\
\hline Secondary sch. (not completed) & 2 & 1.6 \\
\hline Secondary sch. (completed) & 36 & 30 \\
\hline Post secondary & 61 & 50.8 \\
\hline \multicolumn{3}{|l|}{ Child dependency ratio } \\
\hline No dependency & 22 & 18.3 \\
\hline $0.1-0.4$ & 56 & 46.7 \\
\hline $0.5-0.8$ & 28 & 23.3 \\
\hline 0.9 and above & 14 & 11.7 \\
\hline \multicolumn{3}{|l|}{ Farm experience (years) } \\
\hline Less than 10 & 83 & 69.2 \\
\hline $10-19$ & 22 & 18.3 \\
\hline $20-29$ & 15 & 12.5 \\
\hline \multicolumn{3}{|l|}{ Membership of cooperative } \\
\hline Membership & 20 & 16.7 \\
\hline Non membership & 100 & 83.3 \\
\hline \multicolumn{3}{|l|}{ Extension agent' contact } \\
\hline Contact & 3 & 2.5 \\
\hline No contact & 117 & 97.5 \\
\hline
\end{tabular}

Source: Field Survey, 2011.

This indicates that food production in the urban area is mostly subsistence in nature which may likely influence food availability.

Distribution of households by economic factors in Table 3 showed that most respondents $(71 \%)$ had no access to agricultural loan. The income level of the household heads as observed by Ibrahim et al. (2009) affects their food security level. The income earned was also investigated and the analysis showed that most respondents (56\%) earned between $\mathrm{N} 80,000-\mathrm{N} 119,000$ per month.

Table 3: Distribution of Households by Economic Factors

\begin{tabular}{ccc}
\hline Economic factors & $\begin{array}{c}\text { Medium- income Households } \\
\text { Freq. }\end{array}$ \\
\hline Access to Agricultural Loan & 35 & 29.2 \\
Accessible & 85 & 70.8 \\
Not Accessible & & \\
Monthly Income (N) & - & - \\
Less than 40,000 & 28 & 23.4 \\
40,000-79,000.00 & 68 & 56.3 \\
80,000-119,000.00 & 24 & 20 \\
Above 120,000 & &
\end{tabular}




\begin{tabular}{ccc} 
Types of Assets* & & \\
Land & 78 & 65.0 \\
Motor vehicle & 102 & 85.0 \\
Motor cycle & 61 & 50.8 \\
Hand sets & 120 & 100 \\
Radio/T.V. set & 120 & 100 \\
Livestock & 44 & 36.7 \\
Bicycle & 71 & 71.1 \\
Shares & 86 & 59.2 \\
Others(sewing machines, fridges, & 42 & 35 \\
guns etc ) & & \\
\hline
\end{tabular}

\section{* Multiple Responses}

Source: Field Survey, 2011.

Results on Table 3 also showed that mobile phones and radio/television were the most common assets owned these households followed by motor vehicles, shares and land. Amaza et al. (2009) observed that the level of assets ownership is an indication of its endowment and provides a good measure of household resilience in terms of food crisis, resulting from famine, crop failures, or natural disasters. Small proportion of households own assets such as sewing machines, commercial deep freezers and guns.

Table 4: Income generating activities utilized by urban households in ensuring food security.

\begin{tabular}{lcc}
\hline Activities & $\begin{array}{c}\text { Medium- income Households } \\
\text { Freq. }\end{array}$ & $\begin{array}{c}\text { \% } \\
\text { Petty trading }\end{array}$ \\
Barbing/hair weaving & 107 & 24.2 \\
Tailoring & 09 & 2 \\
Wages (civil service) & 24 & 5.4 \\
Crop production & 120 & 27 \\
Agro-Micro processing & 38 & 8.6 \\
Fishing & 68 & 15.4 \\
Poultry & 13 & 2.9 \\
Local livestock husbandry & 52 & 11.7 \\
\hline
\end{tabular}

* Multiple responses existed

Source: Field Survey, 2011

Medium income households in the urban area engaged in different income generating activities. These economic activities provided for immediate needs of the households and also served as buffers during lean periods. Generally, in the study area, respondents are civil servants (27\%).Others income generating activities among the households are petty trading (24\%), agro-processing (15\%) and poultry farming (12\%).

\section{Measure of Calorie Intake and Food Security Status}

Calorie intake and food security status of households in the study area were measured. These derived the cost of minimum energy requirements per adult, the head count ratios, food security levels and aggregate income gap for the household as presented in Table 5. Based on the recommended daily energy levels (L) of 2260 kilocalories, the food security line $(\mathrm{Z})$ for the medium income households in the urban area was estimated at $\$ 74.88$ per day per adult equivalent and $\mathbf{2} 246.4$ per month per adult equivalent. Results of the analysis showed that $67 \%$ of the sampled households in the study area were classified as being food secure. Only $33 \%$ of the sampled households in the study area were food insecure unable to meet the recommended calorie intake of 2260 kilocalories per capita per day subsisting on less than the recommended daily requirements.

Table 5: Summary statistics and food security measures among medium income households

\begin{tabular}{cc}
\hline Households & MIH \\
\hline Variables & Value \\
Cost-of-calorie equation & $\ln \mathrm{X}=\mathrm{a}+\mathrm{bC}$ \\
Constant & $4.316(58.620)^{*}$ \\
Slope coefficient & $0.0000(4.713)$ \\
(L) & $2260 \mathrm{Kcal}$ \\
FAO recommended daily energy Levels & N74.88 per day \\
Food security line Z:Cost of the & N524.16 per week \\
minimum energy requirements per & N2,246.40 per month \\
adult equivalent & N26,956.80per year \\
Head Count (H) & 0.33 (food insecure) \\
Percentage Household & $0.67($ food secure $)$ \\
& $33 \%$ (food insecure) \\
Aggregate income gap (G) & $67 \%$ (food secure) \\
\hline
\end{tabular}


Source: Calculations from OLS estimates and cost-of-calories equation, 2011

*Figures in parenthesis are t-values

Furthermore, the aggregate income gap $(\mathrm{G})$ of -586.24 indicates that the food insecure households would need $\$ 586.24$ to meet their monthly basic food requirements.

\section{Food Security Determinants among Medium Income Households}

The results of the Logit regression for the MIH are presented in Table 6. Analysis of the survey data revealed that 13 out of 16 variables included in the model were significant in explaining the variation in food security status of MIH households. The variables included in the model were age, income, farm size, household size, farm size, farming experience, cooperative membership, level of education, gender of household head, assets, farm enterprise, credit, child dependency ratio, extension agent's contact, hired labour, family labour, and diet diversity. The coefficient of variables in the model were significant at $1 \%(\mathrm{P}<0.01)$ and at $5 \%(\mathrm{P}<0.05)$ levels respectively. This indicates that the model was a good fit to the data. The summary of the significant determinants among the MIH are discussed as follows:

Table 6: Logit Regression Analysis for Medium Income Households

\begin{tabular}{|c|c|c|c|}
\hline \multirow[t]{2}{*}{ Variable } & \multicolumn{3}{|c|}{ Medium income households (MIH) } \\
\hline & Coefficient & Standard Error & t-value \\
\hline Constant & 12.498 & 3.951 & $3.163 * * *$ \\
\hline $\operatorname{AGE}\left(X_{1}\right)$ & .1117 & .0421 & $2.650 * * *$ \\
\hline $\operatorname{HHINC}\left(\mathrm{X}_{2}\right)$ & .0000094 & .00000252 & $3.743 * * *$ \\
\hline $\operatorname{FARMSZ}\left(\mathrm{X}_{3}\right)$ & 2.641 & .928 & $2.845^{* * *}$ \\
\hline $\operatorname{HHSZ}\left(\mathrm{X}_{4}\right)$ & -.4971 & .1620 & $-3.068 * * *$ \\
\hline FARMEXP( $\left(X_{5}\right)$ & .155 & .07675 & $2.023^{* *}$ \\
\hline $\operatorname{COOP}\left(\mathrm{X}_{6}\right)$ & .0664 & 1.0155085 & .065 \\
\hline $\operatorname{EDUC}\left(\mathrm{X}_{7}\right)$ & .1970 & .0750 & $2.627 * * *$ \\
\hline $\operatorname{GEND}\left(\mathrm{X}_{8}\right)$ & .896 & 1.107 & .809 \\
\hline $\operatorname{ASSETS}\left(\mathrm{X}_{9}\right)$ & .0000082 & .00000208 & $3.955 * * *$ \\
\hline FARMENT $\left(\mathrm{X}_{10}\right)$ & 1.001 & .448 & $2.232 * *$ \\
\hline $\operatorname{CREDIT}\left(\mathrm{X}_{11}\right)$ & 3.678 & 1.55 & $2.365^{* *}$ \\
\hline $\operatorname{CDR}\left(\mathrm{X}_{12}\right)$ & -.834 & .503 & -1.655 \\
\hline $\operatorname{EXTAG}\left(\mathrm{X}_{13}\right)$ & 5.340 & 1.677 & $3.183^{* * *} *$ \\
\hline $\operatorname{HLAB}\left(\mathrm{X}_{14}\right)$ & .000238 & .0000657 & $3.636 * * *$ \\
\hline $\operatorname{FLAB}\left(\mathrm{X}_{15}\right)$ & .000269 & .0000813 & $3.308 * * *$ \\
\hline $\mathrm{DD}\left(\mathrm{X}_{16}\right)$ & .402 & .118 & $3.394 * * *$ \\
\hline
\end{tabular}

*** Significant at $1 \%$;** Significant at $5 \%$.

Source: Computer Printout, 2011

Age of household head (AGE): Contrary to expectation, the coefficient of the variable was found to be positive among the MIH at $1 \%$ significant level. This suggests that as household heads in MIH advance in age and in the number of years in service, it is expected that their salary level increases and thus increases their food security status. This result among MIH obviously proved that income significantly determines food access in the study area. Household Income (HHINC): As expected a priori, a significant positive relationship existed between food security level experienced MIH and their income level at $1 \%$. This implies that as the level of income of household heads increases, the food security status of their respective households increases. Income is an important factor to food access especially in the urban where food production is limited and food items purchased at prevailing market prices. Farm Size (FARMSZ): Also, a significant positive relationship as expected existed between food security level experienced by the MIH and farm size at $1 \%$. This indicates that farm size under cultivation largely influenced the level of food availability in these households. Household size (HHSZ): The coefficient of the variable household size was found to be negative as expected and significant at $1 \%$ among MIH. This implies that as the household size increases, food security intensity decreases. Increase in family size necessitates increase in household expenditure on other necessities/utilities which ultimately reduces expenditure on food resulting in food insecurity.

Farming Experience (FARMEXP): The coefficient of farming experience was positive and significant at $5 \%$ level among the MIH. This implies that households' farming experience may likely influence the level of food production that could impact positively on their food security status. Level of Education (EDUC): As a priori expected, the level of education was positive and also significant at $1 \%$ for MIH. The regression result shows that as the level of education of household heads increases, the food security intensity increases and vice versa. This suggests that the level of formal education impact positively the households' nutrition decision thereby reducing food insecurity intensity. Household Assets (HHAST): As expected $a$ priori, a significant positive relationship existed between food security level experienced by MIH and the value of household assets at $1 \%$. This implies that food security status increases in the income groups as assets level increases and vice versa though more significantly among the MIH. 
Production Enterprise (FARMENT): The relationship between household production enterprise and food security was found positive and significant at 5\% level among MIH. These enterprises provide readily available food and/or income to households thereby reducing food insecurity incidence. Credit Access (CREDIT): The coefficient of access to credit is positive and significant at 5\% level among MIH as expected suggesting that access to credit tend to impact positively the food security level of households. Food security status increases as households are economically empowered and vice versa. Extension Agent Contact (EXTAG): The coefficient of extension agent's contact as a priori expected is positive and at $1 \%$ significant level among the MIH households. The regression result suggests that extension agent's contact is important in the adoption of modern farm practices that ultimately influences the level of farm output, hence food security in the study area. Hired Labour (HLAB): Although the coefficient of hired labour was expected to be negative, the result among the MIH runs contrary to expectation. The coefficient of hired labour was positive and significant at $1 \%$ level. This implies that households also engage the services others in agricultural production and other enterprises though they often employ family labour to reduce cost of production. This ultimately increases farm output, all things being equal and hence improves food security status.

Family Labour (FLAB): As expected a priori, a significant positive relationship existed between food security intensity experienced by households and significant at $1 \%$ level. This implies that the impact of family labour in own-food production in these households contributes tremendously to food availability thus reducing food insecurity incidence. Diet Diversity (DD): The coefficient of diet diversity indicated a positive relationship on households' food security status and was found to exert significant influence at $1 \%$ level. Diet diversity is primarily based on food availability and access. This implies that high food diversity is an indication of household food security and vice versa.

\section{Households' Coping Strategies}

Tables 6:Distribution of coping strategies adopted by Medium Income households

\begin{tabular}{|c|c|c|c|c|c|c|}
\hline \multirow[t]{3}{*}{ Strategies } & \multicolumn{6}{|c|}{ Medium income households (MIH) } \\
\hline & \multicolumn{2}{|c|}{ Never } & \multicolumn{2}{|c|}{ Occasionally } & \multicolumn{2}{|c|}{ Always } \\
\hline & Freq & $\%$ & Freq & $\%$ & Freq & $\%$ \\
\hline Rely on less preferred foods & 0 & 0 & 34 & 28.3 & 6 & 5.0 \\
\hline Rely on less expensive foods & 3 & 2.5 & 37 & 30.9 & 0 & 0 \\
\hline Borrow money to buy food stuffs & 40 & 33.3 & 0 & 0 & 0 & 0.0 \\
\hline Borrow food stuffs & 40 & 33.3 & 0 & 0 & 0 & 0.0 \\
\hline Purchase food on credit & 40 & 33.3 & 0 & 0 & 0 & 0.0 \\
\hline Rely on help from relative or friend & 30 & 25.0 & 10 & 8.3 & 0 & 0.0 \\
\hline Limit portions at meal times & 0 & 0 & 30 & 25 & 10 & 8.3 \\
\hline $\begin{array}{l}\text { Ration money to household members to } \\
\text { buy street food }\end{array}$ & 40 & 33.3 & 0 & 0 & 0 & 0.0 \\
\hline $\begin{array}{l}\text { Limit your own intake to ensure children } \\
\text { get enough }\end{array}$ & 0 & 0.0 & 40 & 33.4 & 0 & 0.0 \\
\hline reduce number of meals eaten in a day & 0 & 0.0 & 40 & 33.4 & 0 & 0.0 \\
\hline Skip whole day(s) without eating & 40 & 33.3 & 0 & 0 & 0 & 0.0 \\
\hline
\end{tabular}

Field Survey, 2011

* Multiple responses existed

Coping strategies were employed to cushion the effects of not having enough food to meet the household's needs. Most farming households sampled produced mainly for domestic consumption resulting in low food reserves. These households were either not able to produce enough to last throughout the year or were unable to store enough produce for home consumption throughout the year. The results of households coping strategies are presented in

The distribution of coping strategies adopted by MIH is shown in Table 6. The results revealed that coping strategies such as reliance on less preferred food (28\%), reliance on less expensive foods (31\%), reduction of number of meals per day (33\%) and limiting portions at meal times (33\%) were prominent among households. However, no household in the urban area skipped whole day(s) without food. In line with the views of Quaye (2008) and Adekoya (2009), households in the study area employed both protecting consumption and modifying consumption.

\section{Conclusion And Recommendation}

The results of the study revealed that there was a significant relationship between the socioeconomic characteristics of respondents and their food security status. Access to food was not the problem among MIH but rather affordability and this limited most people to rationing and also consuming lower quality food items. This established the existence of food insecurity in the area and necessitated the engagement of coping strategies. Based on the results of the analysis carried out in this study, the following recommendations are suggested to reduce food insecurity. 
- First, household size had a negative and significant effect on food security level of respondents. Therefore, the government should give adequate priority and attention to policy measures directed towards the provision of better family planning. In view of this, more public enlightenment strategies which bring about attitudinal change are important for MIH in the study area.

-Second, most households have small farm holdings and acquisition of more farm lands for agriculture may likely be difficult in the metropolis. Therefore, households should be encouraged to further diversify their incomes into other income generating activities that would maximize available land and also generate more income thereby increasing food security among households.

\section{References}

[1]. Adekoya, A.E. (2009). Food Insecurity and Coping Strategies among rural households in Oyo State, Nigeria. Journal of Food, Agriculture and Environment. 7 (3\&4): 187- 191.

[2]. Amaza, P.S., Abdoulaye, T., Kwaghe, P.V., and Tegbaru, A, (2009). Changes in household food security and poverty status in PROSAB area of Southern Borno State, Nigeria. International Institute of Tropical Agriculture (IITA) and Promoting Sustainable Agriculture in Borno State (PROSAB). Pp 1-40.

[3]. Babatunde, R.O., Omotosho, O.A., and Sholatan, O.S. (2007). Socio-economic characteristics and food security of farming households in Kwara State, North-Central Nigeria. Pakistan Journal of Nutrition, 6: 49-58

[4]. Food and Agriculture Organization. (2009).Measuring Food Security Using Respondents Perception of Food Consumption Adequacy. Food and AgricultureOrganization of the United Nations: Rome, Italy.

[5]. Federal Office of Statistics (2004).Nigeria Living Standard Survey. Report prepared by FOS in collaboration with EU, World Bank, Department for International Studies. Pp. 9-24.

[6]. Greer, J., and Thorbecke, E. (1986). A methodology for measuring poverty applied to Kenya. Journal of Development Economics 24(1):59-74

[7]. Hall, T. (2002). New Challenges in hunger"-Economic Perspectives Economic J. US Department of Agriculture, 7: 6-8.

[8]. Ibrahim, H., Uba-Eze, N.R., Oyewole, S.O., and Onuk, E.G. (2009). Food Security among Urban Households: A Case Study of Gwagwalada Area Council of the Federal Capital Territory Abuja, Nigeria. Pakistan Journal of Nutrition 8 (6): 810-813.

[9]. Kwaghe, P. V. (2006).Poverty Profile and its Determinants among Farming Households In: Borno State. Nigeria. (Unpublished Ph.D Thesis), University of Maiduguri, Borno State. Pp 22-40.

[10]. Maryah, U. M. (2005). Forage availability and Livestock Management Systems in Semiarid Zone of North East Nigeria. Ph.D. Thesis submitted, Department of Geography, Bayero University, Kano.

[11]. Maziya-Dixton, B., Akinyele, J.O., Oguntona, E.B., Nokoe, S., Sanusi, R.A. and Haris, E. (2004). Nigeria food consumption and nutrition survey (2001-2003) International Institute of Tropical Agriculture Ibadan, Nigeria.

[12]. Nyangwesoi, P.M., Odhaiambo, M.O., Odungari, P., Koriri, M.K., Kipsat, M.J., and Serem, A. K. (2007). Household food security in Vihiga district, Kenya: Determinants of dietary diversity. Proceedings of the $8^{\text {th }}$ African Crop Science Society Conference, El-Minia University, Egypt October 27-31, pp. 1383-1390.

[13]. Oluyole, K.A., Oni, O.A., Omonona, B.T., and Adenegan, K.Q. (2009). Food Security among Cocoa Farming Households of Ondo State, Nigeria. ARPN Journal of Agriculture and Biological Science. 4(5):7-14.

[14]. Quaye, W. (2008). Food Security situation in northern Ghana, Coping Strategies and related Constraints. African Journal of Agricultural Research. Vol. 3(5): 334-342.

[15]. Sanusi, R.A., Badejo, C.A., and Yusuf, B.O. (2006). Measuring Household Food Insecurity in Selected Local Government Areas of Lagos and Ibadan, Nigeria. Pakistan Journal of Nutrition, 5: 62-67. 